Article

\title{
Submission of a WECC DFIG Wind Turbine Model to Spanish Operation Procedure 12.3
}

\author{
Francisco Jiménez-Buendía ${ }^{1}\left(\mathbb{C}\right.$, Raquel Villena-Ruiz ${ }^{2}{ }^{\mathbb{D}}$, Andrés Honrubia-Escribano ${ }^{2}{ }^{\mathbb{D}}$, \\ Ángel Molina-García ${ }^{3}$ (D) and Emilio Gómez-Lázaro ${ }^{2, *(\mathbb{D})}$ \\ 1 Siemens Gamesa Renewable Energy, S.A., 31621 Pamplona, Spain; francisco.jimenez@siemensgamesa.com \\ 2 Renewable Energy Research Institute and DIEEAC-ETSII-AB, Universidad de Castilla-La Mancha, \\ 02071 Albacete, Spain; raquel.villena@uclm.es (R.V.-R.); andres.honrubia@uclm.es (A.H.-E.) \\ 3 Department of Electrical Engineering, Universidad Politécnica de Cartagena, 30202 Cartagena, Spain; \\ angel.molina@upct.es \\ * Correspondence: emilio.gomez@uclm.es; Tel.: +34-967-599-200 (ext. 2418)
}

Received: 9 August 2019; Accepted: 27 September 2019; Published: 30 September 2019

\begin{abstract}
Power systems are currently witnessing a high wind-power penetration due to the development and commissioning of an increasing number of wind-power plants. This new scenario inevitably changes the way power systems are operated, mainly due to the uncertainties associated with wind, with the proper integration of this renewable energy source into the grid emerging as a new challenge. Unlike other highly flexible energy sources that can be used on demand according to the market needs, wind energy production is intermittent and non-dispatchable. In this context, transient stability analyses through the dynamic simulation of wind-turbine models and wind-power plants must be carried out. Moreover, as many countries have their own grid codes, the compliance requirements to connect wind farms to the network may be significantly different, depending on the specific region. In light of the above, this paper addresses the submission to Spanish Operation Procedure 12.3 (PO 12.3), for the first time, of one of the most advanced wind-turbine models, the generic Type 3 or doubly fed induction generator defined by the Western Electricity Coordinating Council (WECC) Second-Generation guidelines. The results show, on the one hand, the notable effect of the transformer inrush current, which influences the accuracy of the behavior of the generic wind-turbine model, and, on the other hand, the inability of the generic model to represent the transient periods of actual wind turbines. However, when the validation criteria is applied at the low-voltage measurement point, the WECC model fully complies with Spanish grid code PO 12.3.
\end{abstract}

Keywords: generic model; grid code; validation; WECC

\section{Introduction}

In order to reduce the tight dependence on fossil fuels used to cover global energy consumption, renewable energy resources are of great importance. In particular, the objectives of the European Union (EU) regarding renewable energy production for 2030 targeted a value of $27 \%$ for the renewable energy consumed in the EU in that year [1]. Thus, it is of prime importance to develop a clear strategy to help achieve this objective, one that fosters the stability required to attract investments and seeks a consensus to promote a higher participation of renewable energies in countries' electricity mix.

Among the different renewable energy sources, wind power has experienced considerable growth in recent years, reaching a total installed capacity of 539,581 MW in 2017 [2]. Europe currently has a total installed capacity of $189 \mathrm{GW}$ of wind power, of which $11.7 \mathrm{GW}$ was installed in 2018 [3]. In particular, Spain is one of the world's leading countries with $23,484 \mathrm{MW}$, ranking fifth in the world and covering approximately 19\% of the average annual electricity demand during 2018 [3]. 
Nevertheless, the unpredictable variability of wind may lead to critical situations during peak demands of energy on the electrical grids, making it necessary for Transmission and Distribution System Operators (TSOs and DSOs, respectively) to plan network operations effectively. Thus, detailed grid operation planning guarantees power supply and forecasts the power compensations that are required from conventional power plants in addition to increasing network reliability and to avoiding voltage and frequency regulation problems.

To deal with this issue, in-depth transient stability analyses of wind turbine (WT) and wind power plant (WPP) models are required. Specifically, the performance of these dynamic simulation models must be assessed against severe grid disturbances such as voltage dips, which may be caused by short circuits or overload periods. In this sense, it is also worth considering the effects of voltage dips on powered systems and industrial equipment, which are discussed in detail in works such as References $[4,5]$. The wide variety of detailed WT simulation models developed by the different WT manufacturers, however, makes it difficult to obtain a generalized and unified response. It was, therefore, necessary to develop generic or standard WT dynamic models able to faithfully represent those actual WT models [6].

In light of the above, the Western Electricity Coordinating Council (WECC), and the International Electrotechnical Commission (IEC), through the WECC Second Generation of Wind Turbine Models [7] and Standard IEC 61400-27-1 [8], respectively, are the two main entities focused on the development of the four generic types of WT technologies currently available in the market: Type 1, with an asynchronous generator directly connected to the grid; Type 2, with an asynchronous generator equipped with a variable rotor resistance directly connected to the grid; Type 3, with a doubly-fed induction generator (DFIG) connected through a back-to-back power converter; and Type 4, with synchronous or asynchronous generators directly connected to the grid through a full-scale power converter.

The WECC report entitled WECC Second Generation of Wind Turbine Models [7], which includes the generic WT simulation models described in the previous paragraph, was published in January 2014. The first edition of this technical report was published four years earlier, in 2010 [9]. It was mainly based on the contribution of a single WT manufacturer, while the second edition featured contributions from different WT manufacturers, thus obtaining generic WT models able to represent a wider range of actual WTs. It should also be highlighted that, while the IEC is more focused on obtaining an optimized behavior of the WT models and, so, their responses are very similar to field measurements, the WECC opts for developing very technically simplified WT simulation models [10], reducing the number of parameters required as far as possible. In this sense, the generic WECC WT simulation models are designed to be studied using positive-sequence power flow and integration time steps in the range of 1 to $5 \mathrm{~ms}$, which is a common time step for transient stability analysis. WECC models also assume that wind speed is constant during the simulation. Hence, they are not intended to represent in detail the transient periods that appear during grid disturbances and may produce short voltage spikes when the faults are cleared. These spikes should therefore be ignored, since they do not represent the transient periods of actual machines and result from the simplification process of the models and the way they interface with the external network. However, these publicly available and simplified WECC WT models are able to provide sufficiently accurate responses using a limited number of parameters and can represent any vendor's WT model, in addition to ensure the same simulation results regardless of the software tool used.

In the specific case of Standard IEC 61400-27-1, the behavior of the WT models may be assessed following the standard's own validation guidelines [11]. However, most countries have their own grid interconnection agreements, i.e., they have developed their own grid codes and their own validation guidelines. In the case of Spain, the Spanish Grid Code, through Operation Procedure 12.3 (PO 12.3) for fault ride-through capability, details the behavior that WPPs must have under grid disturbances, namely voltage dips. Thus, to comply with PO 12.3, a specific procedure for verification, validation, and certification (PVVC) [12] was also developed. The PVVC involves the conduction of certain technical adjustments, such as the implementation of flexible alternating current transmission systems 
(FACTS), in order for the Spanish WPPs to comply with PO 12.3 [13]. Moreover, the responses of these actual WPPs must be analyzed quantitatively by calculating the validation errors following the validation criteria established by the PVVC.

Previous works related to the application of the Spanish grid code, such as References [14,15], perform the complete process of verification and validation of a particular WPP in Spain following the PVVC guidelines, in addition to applying different voltage dips to the actual WTs and analyzing their response according to PO 12.3. However, the present contribution is aimed at complementing the work previously conducted in Reference [16], in which a generic IEC-developed Type 3 WT simulation model was submitted to the Spanish PO 12.3. Thus, the present work addresses the submission of the Type 3 WT model defined by the WECC Second Generation of Wind Turbine Models technical document to the Spanish national grid code requirements. On the one hand, the present work will allow the scope of application of the WECC to be extended. On the other hand, as the WECC Second Generation has not developed a specific validation procedure, the reliability and good performance of the WT simulation model is assessed, for the first time, based on a national grid code requirement. In addition, the present work also contributes to achieving a more widespread use of the generic WT dynamic models developed by the WECC. Moreover, the responses of the generic WECC model, modeled in MATLAB/Simulink, are compared to the field measurements recorded at an actual Spanish WPP composed of Gamesa G52 WTs, as will be further detailed in Section 3.2. Both data series are also compared to the responses of the detailed simulation model corresponding to the Gamesa G52 WT, which was modeled in the PSCAD/EMTDC software tool, and the verification of the PVVC validation criteria is carried out when two different measurement points are considered, also described in Section 3.2.

Furthermore, the present work aims to analyze the modeling limitations of one of the most advanced types of WTs, the Type 3 or DFIG WT, when developed by the WECC. In the cases of non-compliance with PO 12.3, the reasons are thoroughly analyzed, and modeling modifications are proposed.

The paper is structured as follows: Section 2 presents the WT model studied, the generic Type 3 WT model defined by the WECC. Section 3 reviews the requirements imposed by the Spanish grid code to comply with PO 12.3, the procedure that must be followed and the calculation of the validation errors, in addition to explaining how the field measurements were performed. Section 4 describes the results obtained and, finally, Section 5 summarizes the conclusions of the work.

\section{WECC Second Generation of Wind Turbine Models: Type 3}

As will be seen in Section 3, it can be said that most of the works related to the generic WT models have focused on the analysis of their responses under different types of events, mainly voltage dips and reference point changes, and also on the development process followed to obtain them. For instance, works such as References $[17,18]$, among others, conducted in-depth analyses addressing the dynamic behavior of the generic Type 3 WT model defined by Standard IEC 61400-27-1 when subjected to voltage dips, while also describing the main control models which are part of this WT. Regarding the WECC guidelines, works such as References [19-21] addressed the development process of the second generation WT models, while References [22] focused on the validation of a generic Type 3 WECC model against different grid events. Finally, references [23] addressed the validation of wind farm models according to the WECC guidelines. To support this, a more comprehensive literature review of the works addressing the simulation of generic WT simulation models can be found in References [24,25].

In view of the above, due to the lack of studies addressing the submission of the generic WT models to national grid code requirements, which typically differ by country [26] and require validated wind-turbine models to comply with their own interconnection agreements, Reference [16] submitted, for the first time, the generic IEC model to a national grid code. It is, therefore, necessary to complement the work begun in Reference [16] and to submit the generic Type 3 WT model defined by the WECC to 
a specific national grid code, thus expanding the scope of application of this international guideline and the usability of these generic WT models, also analyzing their limitations.

Figure 1 shows the main control models that are part of the generic Type 3 WECC model. The Generator/Converter Model represents a generator model that neglects all the flux dynamics of the machine. It injects the active and reactive components of current, $\mathrm{i}_{\mathrm{p}}$ and $\mathrm{i}_{\mathrm{q}}$, into the external grid. The Exciter/Converter Controls represent the active and reactive power control model in addition to the current limitation system. It provides the active and reactive current commands, $\mathrm{i}_{\mathrm{pcmd}}$ and $\mathrm{i}_{\mathrm{qcmd}}$, to the Generator/Converter Model, mainly based on the active and reactive power reference values, $P_{\text {ref }}$ and $\mathrm{Q}_{\text {ref. }}$. Unlike the generic Type 3 IEC model in which the torque control model is included in the active power control model, the Torque Controls module is set apart from the Exciter/Converter Controls, and provides the reference rotational speed, $\mathrm{w}_{\text {ref }}$, i.e., the speed at which the WT should rotate when a certain value of active power is injected, in addition to the active power reference value, $P_{\text {ref, }}$, which is used by the Exciter/Converter Controls. As in the case of the pitch control model of the generic Type 3 IEC model, the Pitch Controls defined by the WECC calculate the pitch angle required to obtain the active power reference value, i.e., the position angle of the WT blades. The Aerodynamics module provides the Drive-Train model with the mechanical power. Finally, the Drive-Train model, which is a two-mass model that represents the mechanical phenomena between the WT blades and the electric generator, provides the mechanical rotational speed, $\mathrm{w}_{\text {mech }}$.

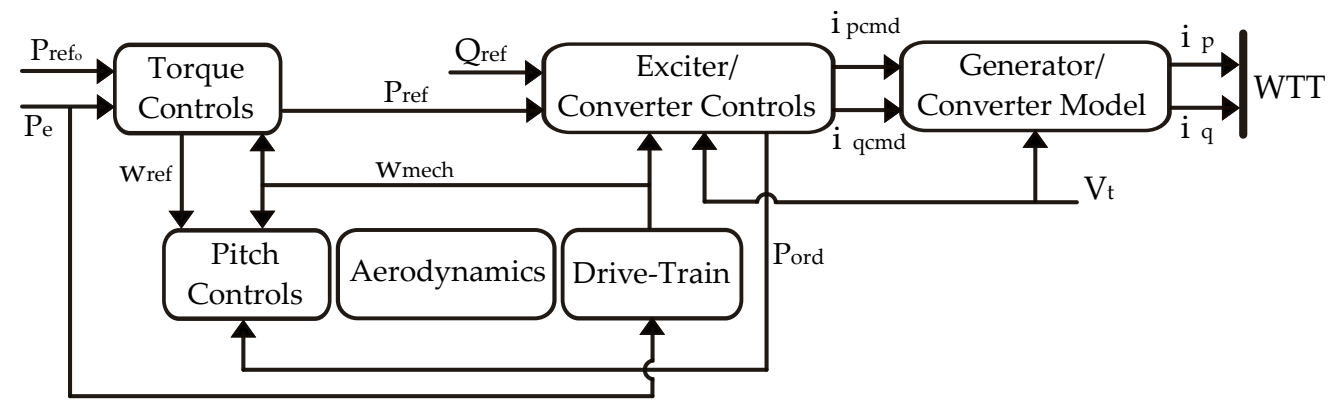

Figure 1. Control models of the generic Type 3 wind-turbine (WT) model based on Western Electricity Coordinating Council (WECC) guidelines [7].

\section{Compliance with Spanish Grid Code Po 12.3}

The generic WT models developed by the WECC have been studied in previous works, such as Reference [27], in which both the Type 3 and Type 4 models are compared to the Type 3 and Type 4 WT models developed by Standard IEC 61400-27-1. Reference [27] also studied the behavior of these generic models against field measurements during voltage dips. In Reference [11], the Type 4 WT model developed by both the WECC and the IEC is validated following the IEC guidelines, comparing their responses to the field measurements collected in an actual WT.

Nevertheless, to the best of the authors' knowledge, there are no works addressing the study of the compliance of the generic WECC WT models with a specific grid code requirement. Therefore, as mentioned in Section 1, the present work addresses the compliance of the Type 3 WT model developed by the WECC with the Spanish grid code PO 12.3, following the PVVC guidelines.

The PVVC criteria, described in Section 3.1, are first applied when comparing the responses of the WECC model with the field measurements of a Gamesa G52 WT. Second, these same criteria are applied to the corresponding detailed simulation model of the actual machine, and the model's performance is compared to the field measurements.

\subsection{Procedure for Verification, Validation and Certification (PVVC)}

For the Spanish WPPs to comply with PO 12.3, different WPP owners, certification entities, WT manufacturers, and the Spanish TSO Red Eléctrica de España formed a working group responsible for the verification of such compliance. To carry out this work, the PPVC technical document was 
prepared, drawing on the active and reactive power responses of different WTs in operation, as well as the active and reactive current responses, mainly during fault and post-fault periods. This allowed the fault ride-through capability requirements to be set, thus developing the PVVC guidelines, the different editions of which may be consulted in Reference [16].

The latest edition of the PVVC (Ed. 11), released in September 2018, is that followed in the present work. As stated in Reference [16], and following the general verification procedure issued by the PVVC [12] (the flowcharts defining the stages for the verification process may be consulted in Reference [14,15]), a three-step process must be followed. First, the wind turbine is tested, second, the wind turbine model is validated, and, third, the wind farm is simulated. However, as the purpose of this work is to study the compliance of the generic Type 3 WT model developed by the WECC with the Spanish PO 12.3, the present work focuses on the first two steps.

Moreover, as Reference [16] provides a detailed analysis of the procedures followed to certify WTs and WPPs in Spain according to the PVVC, the present contribution aims to complement that work by detailing the process of how the field tests are conducted (see Section 3.2). Thus, these works perfectly complement each other and provide a complete overview of the Spanish PO 12.3 in addition to assessing the behavior and limitations of the Type 3 WT simulation model developed by the two main international technical documents related to the wind-energy field: the IEC 61400-27-1 and the WECC Second Generation of Wind Turbine Models.

Before describing characteristics of the field tests, it is important to highlight how the Type 3 WT model is assessed, following the validation procedure issued by the PVVC. Once the field tests are conducted (further detailed in Section 3.2), and the power calculation methodology described in Section 9.2 of the PVVC [12] is applied to obtain the Root Mean Square (RMS) values of the different variables measured, thus obtaining the accredited report, the validation process of the model begins.

The fifth edition of the PVVC (released in June 2009) was the first in which a voltage source could be used for the voltage dip modeling [16]. Thus, a voltage source is implemented along with the WT simulation model to reproduce the instantaneous values of the voltage measured. Moreover, it is also important to note that the time interval used in the simulations must be equal to or less than the time interval associated with the frequency of the sample used during the field tests [12].

Hence, the responses of the WT simulation model and the field tests can now be submitted to the validation criteria. Following the PVVC [12] guidelines, a WT simulation model can be considered validated when, applied at both the active and reactive power responses and in $85 \%$ of the data series analyzed, the absolute value of the difference between the field tests $\left(P_{\text {mea }}\right.$ or $\left.Q_{\text {mea }}\right)$ and the simulation values $\left(P_{\text {sim }}\right.$ or $\left.Q_{\text {sim }}\right)$ do not exceed the nominal value $\left(P_{\text {nom }}\right.$ or $\left.Q_{\text {nom }}\right)$ by $10 \%$ (see Equations (1) and (2)). The time interval or duration of the comparison window to assess the data series must be $1000 \mathrm{~ms}$. The characterization of the different zones during voltage dips is shown in [12].

$$
\begin{gathered}
\Delta P(\%)=\left|\frac{P_{\text {mea }}-P_{\text {sim }}}{P_{\text {nom }}}\right| \cdot 100 \leq 10 \% \\
\Delta Q(\%)=\left|\frac{Q_{\text {mea }}-Q_{\text {sim }}}{Q_{\text {nom }}}\right| \cdot 100 \leq 10 \%
\end{gathered}
$$

This criterion is applied in two cases, the results of which are explained in Section 4: (i) field tests vs. generic WECC WT simulation model; (ii) field tests vs. detailed WT simulation model.

\subsection{Field Tests}

In addition to the validation methodology, the PVVC also sets out the conditions, the equipment and the field measurements required to analyze the compliance of the WT models with the PO 12.3. Thus, the voltage dips must be generated at the actual WT to be tested using an inductive divider voltage dip generator, in which the reactance values $X_{1}, X_{2}$ and $X_{3}$ must be defined [12]. In particular, a medium voltage ride through container (RTC-MV) such as the one defined in [28] is used to conduct the field tests. The values of the three reactances that define the RTC-MV are calculated based on 
the PVVC guidelines [12]. Figure 2 shows a schematic representation of the voltage dip generator connected to the actual WT, including the reactances, the calculation of which is explained below.

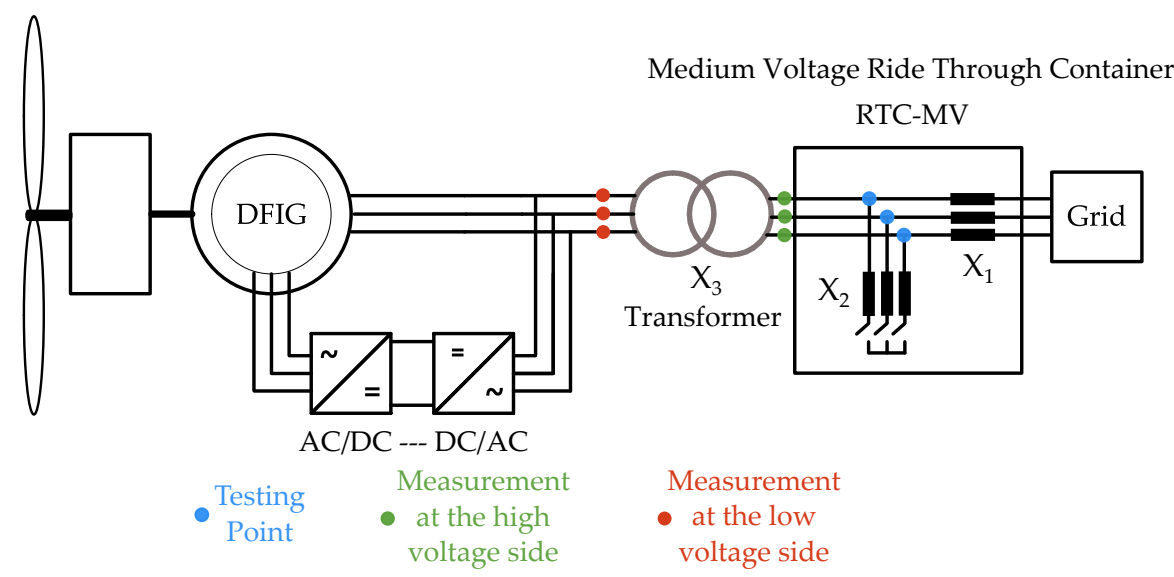

Figure 2. Voltage dip generator mobile test unit connected to the doubly fed induction generator (DFIG) WT.

In Equations (3) and (4), $U_{n}$ is the rated voltage of the network, $Z_{c c}$ is the short-circuit impedance, and $S_{n}^{W T}$ is the rated power of the WT. The $X_{1}$ reactance limits the short-circuit current during the fault. Its value is calculated to obtain a short-circuit power at the testing point greater than or equal to 5 times the power recorded at the WT (see Equation (2)). $X_{2}$ must be adjusted so that the RMS residual voltage $\left(U_{\text {res }}\right)$ at the testing point during the no load test is less than $90 \%$ of the rated voltage $\left(U_{n}\right)$. It is worth noting that the no load test is conducted using the RTC-MV when the WT is switched off. This type of test allows the voltage dip to be characterized without the influence of the WT, since the machine may modify the square profile of the voltage in the cases in which it is operating, injecting active and reactive power.

Hence, the value of $X_{2}$ can be calculated following Equation (3). Moreover, a switching device must be connected to the reactance $X_{2}$ so that the short-circuit required can be generated.

$$
\begin{gathered}
X_{1} \leq \frac{U_{n}^{2}}{5 \cdot S_{n}^{W T}}-Z_{c c} \\
U_{r e s}=U_{n} \cdot\left|\frac{j X_{2}}{\bar{Z}_{c c}+j X_{1}+j X_{2}}\right|
\end{gathered}
$$

Finally, $X_{3}$ must correspond to a transformer or a combination of reactances and transformers, and its value is calculated according to the following criteria:

1. If the WT is not equipped with a step-up transformer: $X_{3}=0$

2. If the WT is equipped with a step-up transformer, there are two possibilities:

- The value of the short-circuit impedance of the step-up transformer will be assigned to $X_{3}$.

- The value of the short-circuit impedance of the step-up transformer with a tolerance of $\pm 20 \%$ at a normalized value.

In the present paper, the WT is tested under a three-phase isolated voltage dip. First, the WT operates at full load conditions of $0.93 \mathrm{pu}$. This is in line with the requirements established by the PVVC for these cases, in which the load conditions are defined as a range of the active rated power of the WT: between $80 \%$ and $100 \%$ of $P_{n}$ for full load conditions. Second, the WT operates at partial load conditions of $0.20 \mathrm{pu}$, a value which also complies with the requirements of the PVVC: between $10 \%$ and $30 \%$ of $P_{n}$ for partial load conditions. Moreover, in the case of three-phase faults, the conditions of the PVVC establish that: (i) that the voltage dip duration must be higher than or equal to $500 \mathrm{~ms}$ 
minus the time tolerance (50 ms); (ii) that the residual voltage must be equal to or less than $20 \%$ plus the voltage tolerance $(+3 \%)$ [12].

Once the voltage dip is generated, the three-phase voltages and powers are measured and the positive-sequence values are calculated, since the generic WECC WT models are positive-sequence dynamic models [7].

Moreover, the measurement and testing points may or may not coincide. In this case, the testing point is located upstream from the transformer, as shown in Figure 2 (in blue), and two measurement points are considered, located at the low- and high-voltage (HV) sides of the transformer (in red and green, respectively). Therefore, when the measurement point is located at the HV side of the transformer and coincides with the testing point, both the WT and the transformer models will be considered validated if the validation criteria described in Section 3.1 are fulfilled. In contrast, when the measurement point is located at the low-voltage (LV) side, only the WT model will be considered validated if the validation criteria are complied with.

Section 4 details the results obtained when the verification process of the PVVC validation criteria was applied to both the WECC and the detailed simulation models, considering the HV side as well as the LV side measurement points.

\section{Results}

A three-phase voltage dip with a duration of $570.5 \mathrm{~ms}$ was applied on the actual WT (Gamesa G52) working at full load conditions of $0.93 \mathrm{pu}$ and partial load conditions of $0.20 \mathrm{pu}$, following the methodology described in Section 3.2. The generic WECC model and the detailed WT simulation model were implemented in the software tools MATLAB/Simulink and PSCAD/EMTDC, respectively. The positive-sequence values of the voltage dip measured were then reproduced in both simulation models by using a voltage-dependent source, as mentioned in Section 3.1. This is known as the play-back validation approach [29], as it allows the voltage dip to be accurately reproduced.

The residual voltage, shown in Figure 3, was $19.66 \%$ for phase A, $17.75 \%$ for phase B, and $19.91 \%$ for phase $\mathrm{C}$. In this same figure, the red line represents the voltage dip measured at the actual WT, the blue line represents the voltage dip reproduced by the detailed WT model, and the orange line corresponds to the voltage dip reproduced by the generic WECC WT simulation model. As can be seen, there exists a good correlation between the three signals, so it can be said that the voltage dip measured was accurately reproduced at both WT simulation models.

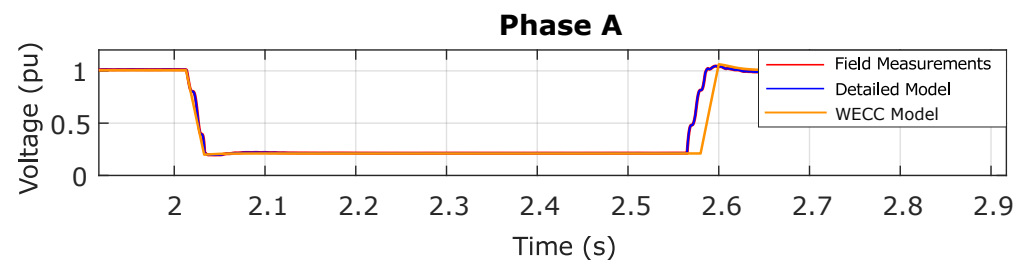

Phase B

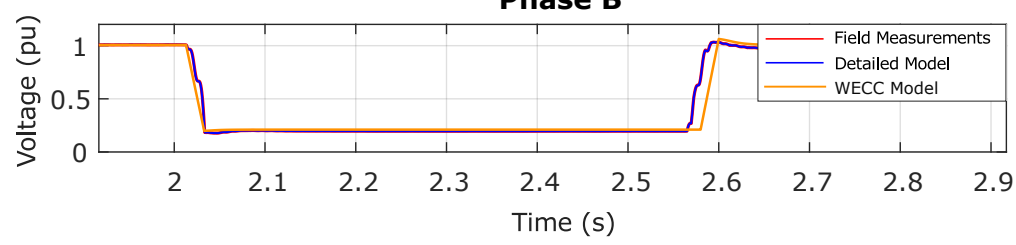

Phase C

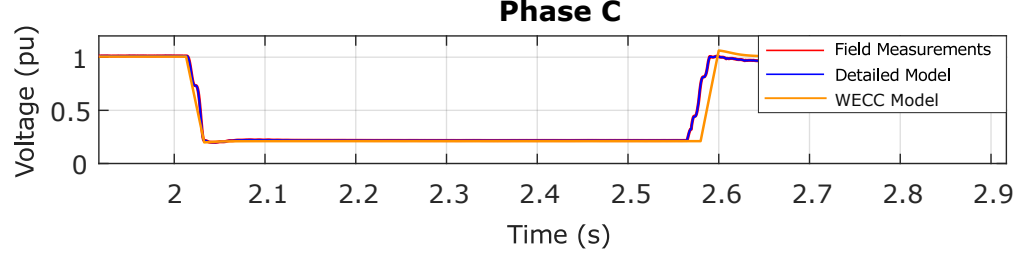

Figure 3. Root Mean Square (RMS) voltage in each phase: measured and simulated. 
As explained in Section 3.2, two different measurement points were considered for the application of the PVVC criteria in both the WECC and the detailed simulation models (see Figure 2): first, the high-voltage $(\mathrm{HV})$ point $(20 \mathrm{kV})$, i.e., the point that coincides with the testing point, and second, the LV point $(690 \mathrm{~V})$, downstream from the transformer.

In order to properly analyze and interpret the results obtained, and based on the information on the PVVC report and the equations shown in Section 3.1, the rated value to apply the validation criteria was $1 \mathrm{pu}$. Therefore, for at least $85 \%$ of the data series, the maximum deviation allowed $(10 \%)$ was $0.1 \mathrm{pu}$, as will be reflected in the results tables included in Section 4.

\subsection{Verification of the PVVC Criteria at the Testing Point: Measurement Point at HV Side}

Table 1 shows the results for the application of the PVVC validation criteria at the HV measurement point (coinciding with the testing point, see Figure 2) in the cases of the WECC model and the detailed model. The validation process therefore affected both the transformer and the WT model. Hence, it was also necessary to implement and simulate the transformer along with the generic and detailed models. In the case of the generic WECC WT, the transformer was simply modeled through an impedance [14].

Table 1. Verification of the procedure for verification, validation, and certification (PVVC) validation criteria applied to the WECC and detailed WT models at the testing point, operating at full load conditions: $20 \mathrm{kV}$, measurement point at $\mathrm{HV}$ side.

\begin{tabular}{cccccc}
\hline \multirow{2}{*}{ WT Model } & Magnitude & $\begin{array}{c}\text { Max. Deviation } \\
(\mathbf{p u})\end{array}$ & $\begin{array}{c}\text { Mandatory Points } \\
\text { Below 0.1 pu (\%) }\end{array}$ & $\begin{array}{c}\text { Points Below } \\
\mathbf{0 . 1} \mathbf{~ p u ~ ( \% )}\end{array}$ & Compliance \\
\hline \multirow{2}{*}{ WECC } & Active Power, P & 0.10 & 85 & 81 & $\boldsymbol{X}$ \\
& Reactive Power, Q & 0.10 & 85 & 59 & $\boldsymbol{X}$ \\
\hline \multirow{2}{*}{ Detailed } & Active Power, P & 0.10 & 85 & 91 & $\checkmark$ \\
& Reactive Power, Q & 0.10 & 85 & 90 & $\checkmark$ \\
\hline
\end{tabular}

Regarding the WECC WT model results depicted in Table 1, only $81 \%$ of the points within the data series analyzed complied with the validation criteria in the case of active power, while an even lower number of points, $59 \%$, complied with the validation criteria in the case of reactive power. The PVVC validation criteria were, therefore, not complied with either of these cases when applied at the testing or HV measurement points, so that the WECC and the transformer models could not be validated.

Concerning the detailed WT simulation model, the results of which are also shown in Table 1, both the active and the reactive power responses complied with the PVVC, since $91 \%$ and $90 \%$ of the data series analyzed fulfilled the validation criteria, respectively.

Figure 4 shows the active and reactive power responses of the WECC and detailed WT simulation models when subjected to the measured voltage dip, along with the field tests recorded at the testing point. As observed in Figure 4a, there exists a good correlation between the active power responses of the WECC model and the field measurements. However, the largest differences were found when the fault was cleared, i.e., during the transient period responses of the generic WT model. This is because the WECC model only used a current versus voltage lookup table and a first-order filter, while the detailed model (or full-order model) included a fifth-order generator model in addition to a full-order converter controller with Proportional Integral (PI) controllers for active and reactive power models that used different parameters for normal and transient operation. Therefore, generic models are not specifically designed to represent the transient periods that appear during the operation of actual WTs. However, to improve the representation of these transient periods by the generic WECC WT while keeping its simplified approach, a modification was proposed within the Generator/Converter Model, including an electromagnetic transient resistance, Rs, and reactance, $\mathrm{X}_{\mathrm{s}}$, in order to simplify modeling the transients of the actual WT. 


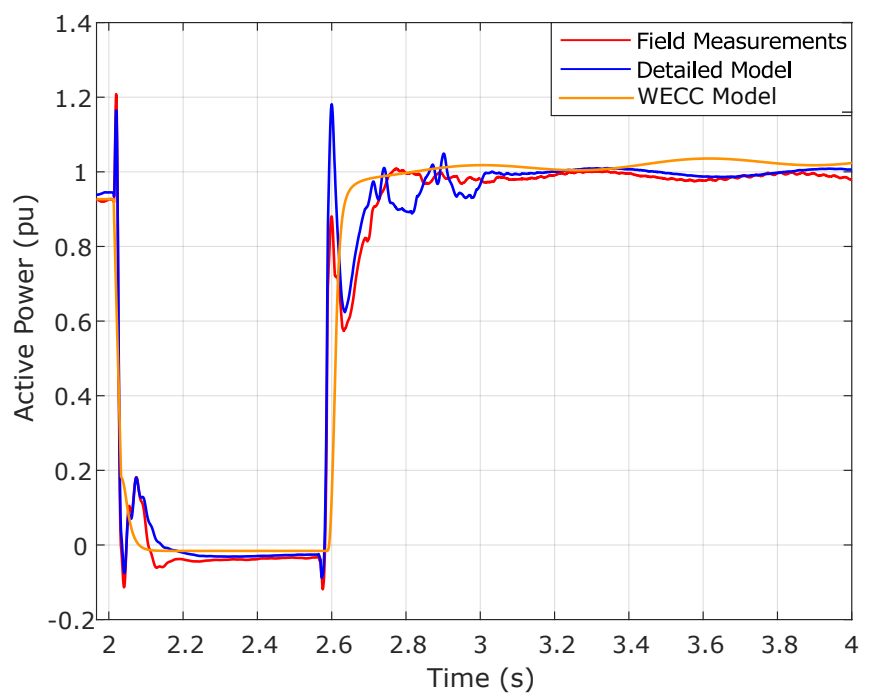

(a)

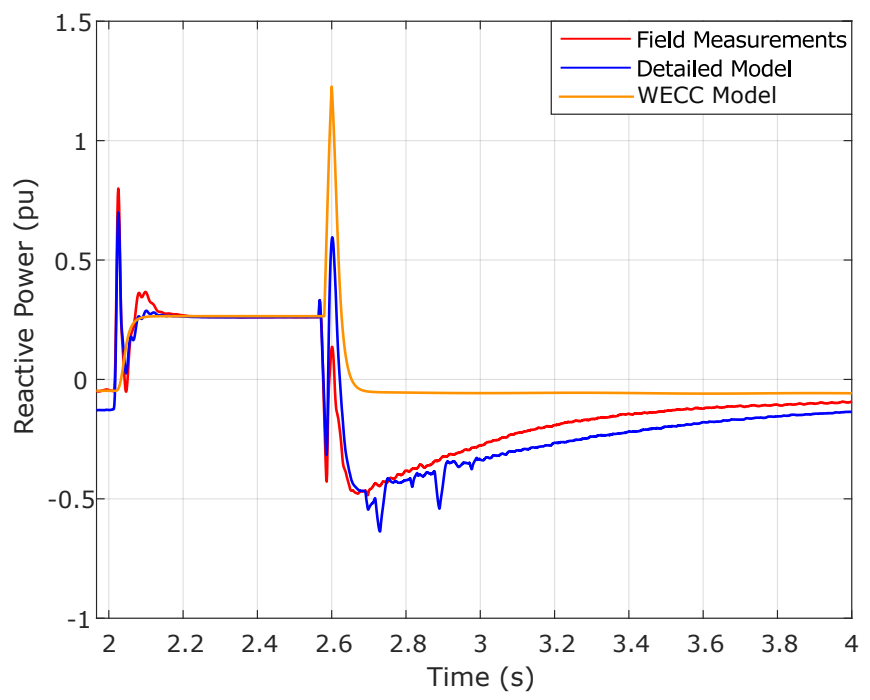

(b)

Figure 4. Active and reactive power at measurement point $1(20 \mathrm{kV})$. WT operating at full load conditions.

(a) active power; (b) reactive power.

Furthermore, those significant differences during the transient responses, also observed in the period from $2.57 \mathrm{~s}$ to $3.00 \mathrm{~s}$ in Figure 4a between the detailed and the WECC WT models, were due to the active power control model of the full-order model WT changed from a voltage dip mode to a normal operation mode at $3.00 \mathrm{~s}$. After that, the differences observed were influenced by the active power performance of the WECC WT model up to that point, which caused drive train oscillations of different phase than those observed for the full-order or detailed model and for the field tests. Moreover, there are also large differences in the Torque Controls model and the generator speed filters between the highly simplified WECC WT model and the full-order WT model, which also contributed to those differences in the active power responses after the fault clearance.

The issues concerning the proper representation of transient periods by generic models also applies to the reactive power response of the WECC WT model. However, this situation was exacerbated by the fact that generic models are also unable to represent the fundamental component of the transformer inrush current, which in this case is reflected in the measurements. The differences in the reactive power responses can be clearly identified in Figure $4 \mathrm{~b}$. Once the fault was cleared at $2.57 \mathrm{~s}$, the actual WT presented a reactive power consumption peak of almost $-0.5 \mathrm{pu}$ and then gradually 
recovered, while the WECC model presented a constant consumption of reactive power during the whole post-fault period. The effects of the transformer inrush current are also supported by the graphic results in Section 4.2, in which the LV measurement point is used to apply the validation criteria and the transformer is no longer considered, Figure $5 b$.

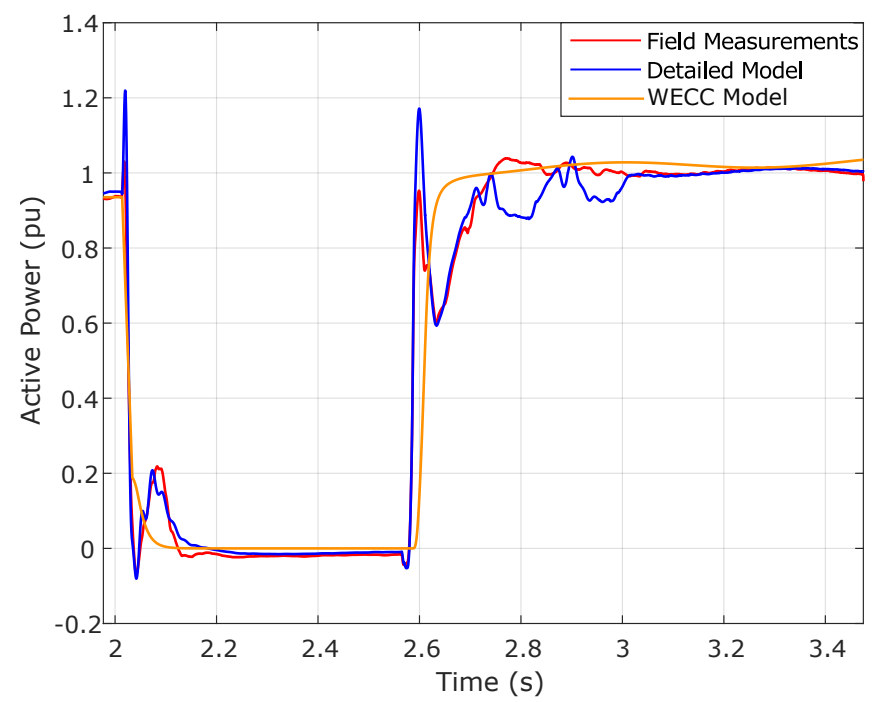

(a)

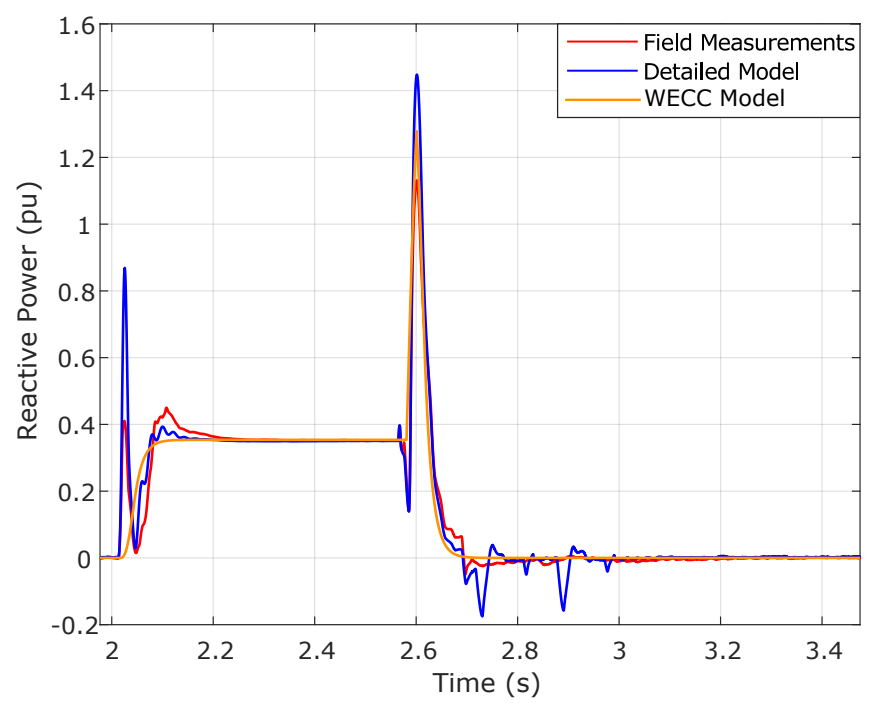

(b)

Figure 5. Active and reactive power at measurement point $2(690 \mathrm{~V})$. WT operating at full load conditions.

(a) active power; (b) reactive power.

Finally, as can also be observed in Figure 4, both the transformer inrush current and the transient periods were reasonably well represented by the detailed WT simulation model, presenting a more accurate behavior than that of the generic WECC WT model. However, there still exist certain inevitable differences between the detailed model and the field measurements because the comparison was performed between an actual machine and a simulation model. Therefore, the detailed WT and transformer models were validated according to Spanish PO 12.3.

\subsection{Verification of the PVVC Criteria at the LV Measurement Point}

No additional validation analyses were required in the case of the detailed WT simulation model, since it already complied with the PVVC criteria when applied at the HV measurement—or 
testing-point. However, taking into account the non-compliance situation of the generic WECC model at this same measurement point, Table 2 presents the results for the application of the PVVC validation criteria at the LV measurement point (see Figure 2) applied to the WECC model. It is important to note that, in this case, the transformer was no longer considered in the validation process, since its effects were already reflected in the measurements performed.

Table 2. Verification of the PVVC validation criteria applied to the WECC WT model at the low-voltage (LV) measurement point, operating at full load conditions: $690 \mathrm{~V}$.

\begin{tabular}{cccccc}
\hline WT Model & Magnitude & $\begin{array}{c}\text { Max. Deviation } \\
(\mathbf{p u})\end{array}$ & $\begin{array}{c}\text { Mandatory Points } \\
\text { Below 0.1 pu (\%) }\end{array}$ & $\begin{array}{c}\text { Points Below } \\
\mathbf{0 . 1} \mathbf{~ p u ~ ( \% )}\end{array}$ & Compliance \\
\hline \multirow{2}{*}{ WECC } & Active Power, P & 0.10 & 85 & 81 & $\boldsymbol{X}$ \\
& Reactive Power, Q & 0.10 & 85 & 90 & $\checkmark$ \\
\hline
\end{tabular}

Concerning the validation results shown in Table 2, the non-compliance situation of the generic WECC model with the validation criteria was reversed in the case of reactive power, as was anticipated in Section 4.1. While only $59 \%$ of the data series analyzed complied with the criteria at the testing point, $90 \%$ complied with the validation requirements at the LV measurement point. The WECC WT model was therefore considered validated in this case for the reactive power response.

Figure 5 shows the active and reactive power responses of both the WECC and the detailed WT simulation models when subjected to the specified fault, along with the field tests when the measurements were performed at the LV side.

The good performance of the WECC WT simulation model in the case of reactive power when the measurements were performed at the LV side is clearly corroborated by the graphic results shown in Figure $5 \mathrm{~b}$. When the fault was cleared, unlike the previous case, the actual WT model did not consume reactive power (although there were still transient periods) because the effects of the fundamental component of the transformer inrush current were no longer reflected in the measurements. Therefore, the WECC WT model, which is unable to emulate those effects, fitted the field tests much better when the measurements were performed downstream the transformer.

Regarding the active power, still only $81 \%$ of the data series analyzed complied with the PVVC requirements (see Table 2), so the non-compliance situation was not reversed in this case. As occurred when the measurement and testing points coincided, this was due to the inability of the generic WT model to emulate the transient periods of the actual WT, Figure $5 \mathrm{a}$.

\subsection{Verification of the PVVC Criteria at the HV and LV Measurement Points: WT Operating at Partial Load Conditions}

Sections 4.1 and 4.2 presented the results of the verification of the PVVC validation criteria applied to the WECC generic WT model at both the HV and LV measurement points, respectively, when the WT operates at full load conditions. The results obtained were extensively analyzed, as were the reasons that led to the situations of non-compliance.

However, in order to support the conclusions obtained and enrich the results section, a new case study was added: the verification of the PVVC criteria when the WT operates at partial load conditions of $0.20 \mathrm{pu}$. As mentioned at the beginning of Section 4, the same three-phase voltage dip as that shown in Figure 3 was applied on the WT operating at partial load conditions.

Table 3 shows the percentage of points that were below the maximum deviation allowed when the PVVC criteria was applied at the HV (or testing) point (see Figure 2). In this case, both case did not comply with the validation criteria, since only $84 \%$ and $61 \%$ of the points within the data series analyzed present a deviation below $0.1 \mathrm{pu}$ for the active and reactive power responses, respectively.

The numerical results are supported by the graphic results shown in Figure 6. In the case of active power, as shown in Figure 6a, the inability of the generic WT (orange line) to represent the transient periods of the actual WT (blue line), especially at the beginning and clearance of the fault, can be 
clearly observed. As in the case of the WT operating at full load conditions, the representation of these transient periods would improve if the Generator/Converter Model of the WECC generic model included an electromagnetic transient resistance and reactance, as mentioned in Section 4.1.

Table 3. Verification of the PVVC validation criteria applied to the WECC WT model at the testing point, operating at partial load conditions: $20 \mathrm{kV}$, measurement point at $\mathrm{HV}$ side.

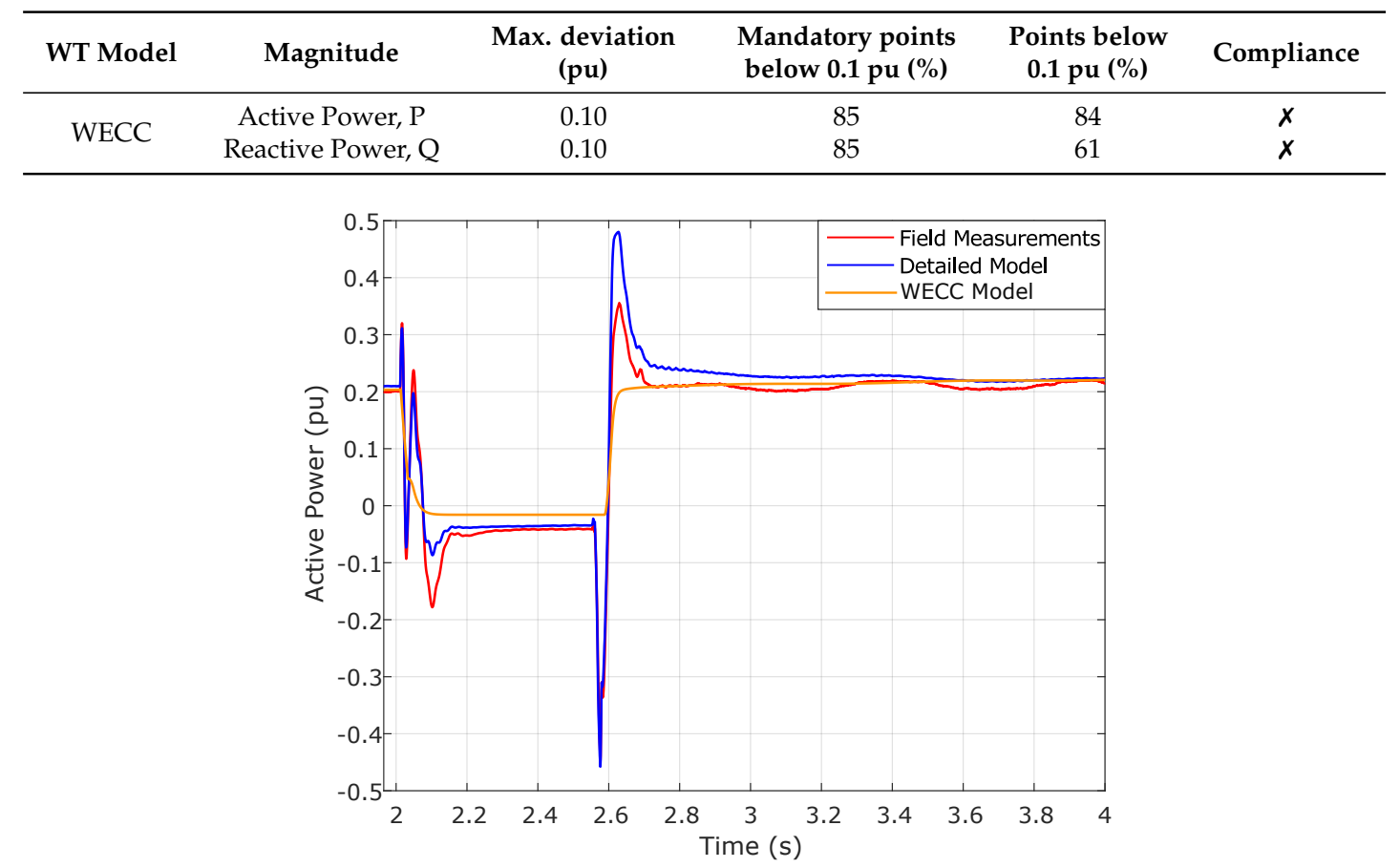

(a)

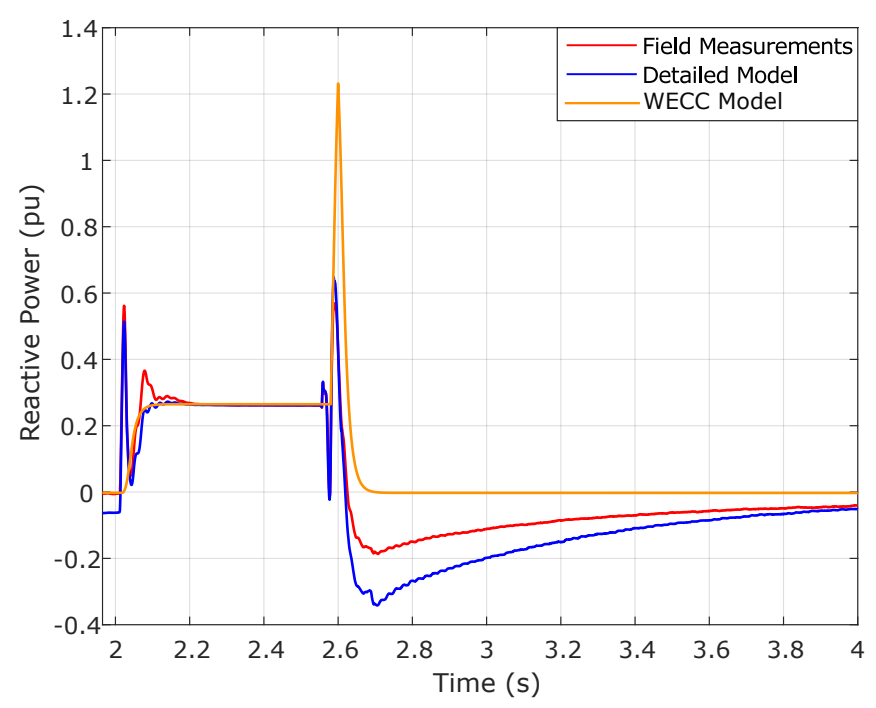

(b)

Figure 6. Active and reactive power at measurement point $1(20 \mathrm{kV})$. WT operating at partial load conditions. (a) active power; (b) reactive power.

The reactive power response also failed to comply with the PVVC criteria when the WT operated at partial load conditions (Figure 6b). In addition to the lack of accuracy of the generic WT model in representing the transient periods, the inability of the model to represent the transformer inrush current is also a key factor which explains the low percentage of points that comply with the validation requirements $(61 \%$, Table 3$)$ and the low accuracy in the reactive power response. 
The largest differences were found from $2.60 \mathrm{~s}$ onward (Figure $6 \mathrm{~b}$ ), since the fundamental component of the transformer inrush current is reflected in both the detailed WT model and the field measurements during that period and the WECC generic model was unable to represent it, remaining around zero.

Table 4 depicts the numerical results when the PVVC validation criteria was applied at the LV measurement point (see Figure 2) and the WT operated at partial load conditions. In this case, both the active and the reactive power response complied with PO 12.3, since $88 \%$ and $90 \%$ of the points analyzed present a deviation below $0.1 \mathrm{pu}$. The non-compliance situations have thus reversed, and Figure 7 supports the improved behavior of the generic WT model.

While there were no significant differences in the active power response (Figure 7a), compared to the previous case (Figure 6a), a meaningful improvement in the reactive power behavior was observed when the LV measurement point was considered for the application of the validation criteria (see the differences between Figures $6 \mathrm{~b}$ and $7 \mathrm{~b}$ ). As explained in Section 4.2, the effects of the fundamental component of the transformer inrush current were no longer considered in the measurements and therefore the generic WECC WT model fitted better to the field tests.

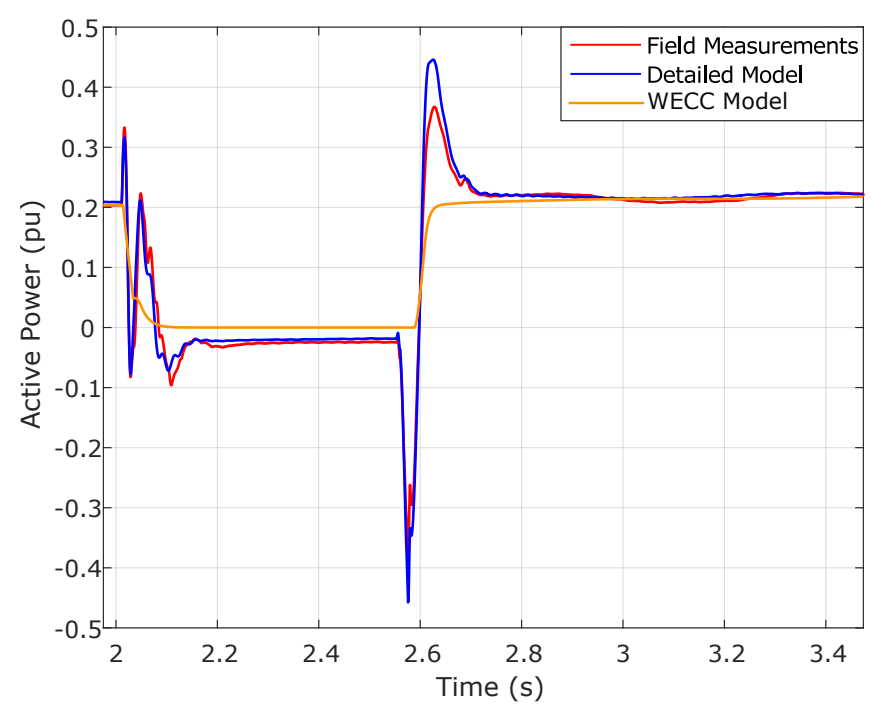

(a)

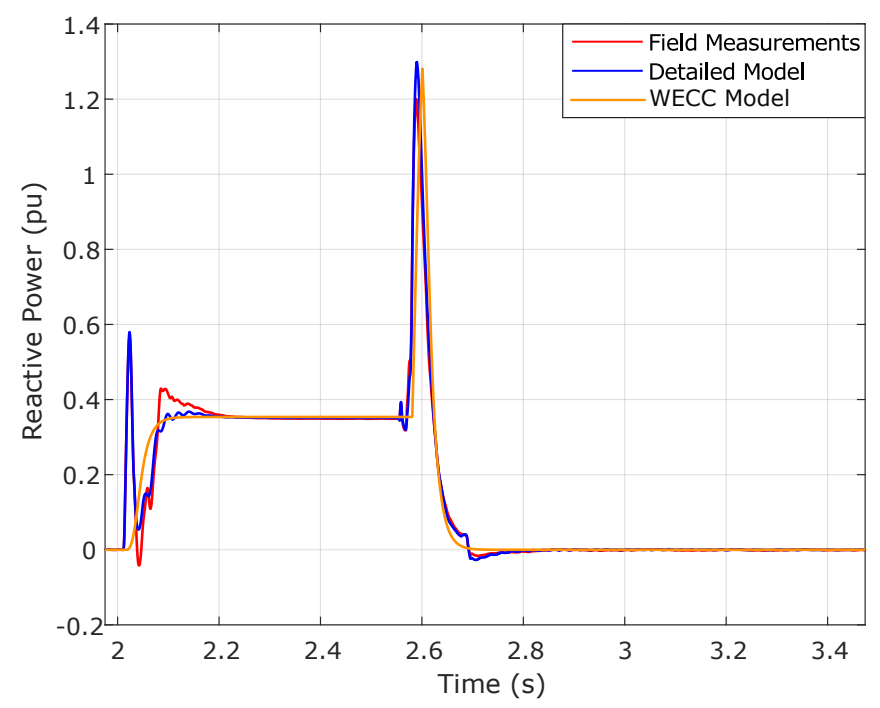

(b)

Figure 7. Active and reactive power at measurement point $2(690 \mathrm{~V})$. WT operating at partial load conditions. (a) active power; (b) reactive power. 
Table 4. Verification of the PVVC validation criteria applied to the WECC WT model at the LV measurement point, operating at partial load conditions: $690 \mathrm{~V}$.

\begin{tabular}{cccccc}
\hline WT Model & Magnitude & $\begin{array}{c}\text { Max. deviation } \\
(\mathbf{p u})\end{array}$ & $\begin{array}{c}\text { Mandatory points } \\
\text { below 0.1 pu (\%) }\end{array}$ & $\begin{array}{c}\text { Points below } \\
\mathbf{0 . 1} \mathbf{~ p u ~ ( \% )}\end{array}$ & Compliance \\
\hline \multirow{2}{*}{ WECC } & Active Power, P & 0.10 & 85 & 88 & $\checkmark$ \\
& Reactive Power, Q & 0.10 & 85 & 90 & $\checkmark$ \\
\hline
\end{tabular}

\section{Conclusions}

The present work submitted the Type 3 WT model defined by the WECC to Spanish PO 12.3 by applying the PVVC. The WECC DFIG WT model was implemented in MATLAB/Simulink, being subjected to a three-phase voltage dip first applied and later measured at an actual Gamesa G52 WT operating at both full load and partial load conditions. Applying the validation criteria established by the PVVC, the WECC model was then compared with the measurements of the actual WT and its corresponding detailed simulation model. Furthermore, the verification of the PVVC validation criteria was applied at two different measurement points, the HV measurement point (corresponding to the testing point and considering the power transformer) and the LV measurement point (located downstream the transformer).

The detailed WT simulation model broadly complied with the validation criteria established by the PVVC for the active and the reactive power responses when applied at the HV measurement point. Hence, both the detailed WT and transformer models were considered validated according to Spanish PO 12.3.

Nevertheless, regarding the WECC generic WT model, when the criteria were applied at the HV measurement point, the requirements were not complied with, since only $81 \%$ and $59 \%$ of the points were below the maximum deviation allowed for the active and the reactive power responses, respectively. The largest differences were found, on the one hand, when the fault was cleared, i.e., during the transient periods; and, on the other hand, during the post-fault period in the reactive power response. This large difference in the reactive power responses between the field measurements and the WECC model was mainly due to the inability of the generic WT models to represent the fundamental component of the transformer inrush current. Thus, neither the generic WECC WT model nor the generic transformer were considered validated when the criteria were applied at the testing point.

On the other hand, when the PVVC validation criteria was applied at the LV measurement point, the reactive power response did comply with PO 12.3. In contrast, the active power still failed to comply with the established requirements. This non-compliance situation was again mainly due to the inaccurate representation of the transient periods. However, the present paper proposed a modeling modification to improve the representation of the transient periods that appear in the actual WT: including an electromagnetic transient resistance and reactance within the generator model of the WECC WT to be able to model the transients in a simplified way.

Finally, it must be noted that, in general terms, the same conclusions drawn from the case study in which the WT operates at full load conditions can be extrapolated to the results obtained when the WT operates at partial load conditions.

Author Contributions: Conceptualization, F.J.-B. and E.G.-L.; Investigation, R.V.-R. and F.J.-B.; Methodology, R.V.-R., F.J.-B. and A.H.-E.; Project administration, E.G.-L.; Supervision, F.J.-B., A.H.-E., Á.M.-G. and E.G.-L.; Writing-original draft, R.V.-R.

Funding: This work was supported by the Spanish Ministry of Economy and Competitiveness and European Union FEDER, which supported this work under Project ENE2016-78214-C2-1-R, as well as the Agreement signed between the UCLM and the Council of Albacete to foster Research in the Campus of Albacete.

Acknowledgments: The authors would also like to express their gratitude to the wind turbine manufacturer Siemens Gamesa Renewable Energy for the technical support received.

Conflicts of Interest: The authors declare no conflict of interest. 


\section{Abbreviations}

The following abbreviations are used in this manuscript:

$\begin{array}{ll}\text { DFIG } & \text { Doubly-Fed Induction Generator } \\ \text { DSO } & \text { Distribution System Operator } \\ \text { EU } & \text { European Union } \\ \text { FACTS } & \text { Flexible Alternating Current Transmission Systems } \\ \text { HV } & \text { High Voltage } \\ \text { IEC } & \text { International Electrotechnical Commission } \\ \text { LV } & \text { Low Voltage } \\ \text { PI } & \text { Proportional Integral } \\ \text { PO } & \text { Operation Procedure } \\ \text { PVVC } & \text { Procedure for Verification, Validation and Certification } \\ \text { RMS } & \text { Root Mean Square } \\ \text { RTC-MV } & \text { Medium Voltage Ride Through Container } \\ \text { TSO } & \text { Transmission System Operator } \\ \text { WECC } & \text { Western Electricity Coordinating Council } \\ \text { WPP } & \text { Wind Power Plant } \\ \text { WT } & \text { Wind Turbine }\end{array}$

\section{References}

1. EUCO. European Council (23 and 24 October 2014)—Conclusions; Technical Report; European Council: Brussels, Belgium, 2014.

2. GWEC. Global Wind Statistics 2017; Technical Report; Global Wind Energy Council: Brussels, Belgium, 2018.

3. EWEA. Wind Energy in Europe in 2018. Trends and Statistics; Technical Report; European Wind Energy Association: Brussels, Belgium, 2018.

4. Carbone, G.; Ceccarelli, M.; Fabrizi, C.; Varilone, P.; Verde, P. Effects of Voltage Dips on Robotic Grasping. Robotics 2019, 8, 28. [CrossRef]

5. Honrubia-Escribano, A.; Gómez-Lázaro, E.; Molina-García, A.; Fuentes, J. Influence of voltage dips on industrial equipment: Analysis and assessment. Int. J. Electr. Power Energy Syst. 2012, 41, 87-95. [CrossRef]

6. Fortmann, J.; Engelhardt, S.; Kretschmann, J.; Feltes, C.; Janßen, M.; Neumann, T.; Erlich, I. Generic simulation model for DFIG and full size converter based wind turbines. In Proceedings of the 9th International Workshop on Large-Scale Integration of Wind Power, Quebec City, QC, Canada, 18-19 October 2010.

7. WECC. WECC Second Generation of Wind Turbines Models Guidelines; Technical Report; Western Electricity Coordinating Council: Salt Lake City, UT, USA, 2014.

8. IEC. Electrical Simulation Models-Wind Turbines; IEC 61400-27-1; IEC: Geneva, Switzerland, 2015.

9. WECC. WECC First Generation of Wind Turbines Models Guidelines; Technical Report; Western Electricity Coordinating Council: Salt Lake City, UT, USA, 2010.

10. Behnke, M.; Ellis, A.; Kazachkov, Y.; McCoy, T.; Muljadi, E.; Price, W.; Sanchez-Gasca, J. Development and Validation of WECC Variable Speed Wind Turbine Dynamic Models for Grid Integration Studies; Technical Report; National Renewable Energy Lab.: Golden, CO, USA, 2007.

11. Lorenzo-Bonache, A.; Honrubia-Escribano, A.; Jimenez, F.; Gomez-Lazaro, E. Field Validation of Generic Type 4 Wind Turbine Models Based on IEC and WECC Guidelines. IEEE Trans. Energy Convers. 2018, 34, 933-941. [CrossRef]

12. AEE. Procedimientos de Verificación, Validación y Certificación de los Requisitos del PO 12.3 y P.O.12.2. Sobre la Respuesta de las Instalaciones Eólicas y Fotovoltaicas Ante Huecos de Tensión, 11th ed.; Asociación Empresarial Eólica: Madrid, Spain, 2018. (In Spanish)

13. AEE. Informe Sobre la Situación Actual y la Problemática Para la Adecuación de los Parques Existentes a los Requisitos Previstos por el P.O.12.3; Technical Report; Asociación Empresarial Eólica: Madrid, Spain, 2009.

14. Jimenez, F.; Gómez-Lázaro, E.; Fuentes, J.A.; Molina-García, A.; Vigueras-Rodríguez, A. Validation of a double fed induction generator wind turbine model and wind farm verification following the Spanish grid code. Wind Energy 2012, 15, 645-659. [CrossRef] 
15. Jiménez, F.; Gómez-Lázaro, E.; Fuentes, J.A.; Molina-García, A.; Vigueras-Rodríguez, A. Validation of a DFIG wind turbine model submitted to two-phase voltage dips following the Spanish grid code. Renew. Energy 2013, 57, 27-34. [CrossRef]

16. Villena-Ruiz, R.; Jiménez-Buendía, F.; Honrubia-Escribano, A.; Molina-García, Á.; Gómez-Lázaro, E. Compliance of a Generic Type 3 WT Model with the Spanish Grid Code. Energies 2019, 12, 1631. [CrossRef]

17. Lorenzo-Bonache, A.; Villena-Ruiz, R.; Honrubia-Escribano, A.; Molina-García, A.; Gómez-Lázaro, E. Comparison of a standard type 3B WT model with a commercial build-in model. In Proceedings of the 2017 IEEE International Electric Machines and Drives Conference (IEMDC), Miami, FL, USA, 21-24 May 2017; IEEE: Piscataway, NJ, USA, 2017; pp. 1-6.

18. Lorenzo-Bonache, A.; Villena-Ruiz, R.; Honrubia-Escribano, A.; Gómez-Lázaro, E. Operation of active and reactive control systems of a generic Type 3 WT model. In Proceedings of the 2017 11th IEEE International Conference on Compatibility, Power Electronics and Power Engineering (CPE-POWERENG), Cadiz, Spain, 4-6 April 2017; IEEE: Piscataway, NJ, USA, 2017; pp. 606-610.

19. Ellis, A.; Kazachkov, Y.; Muljadi, E.; Pourbeik, P.; Sanchez-Gasca, J. Description and technical specifications for generic WTG models-A status report. In Proceedings of the 2011 IEEE/PES Power Systems Conference and Exposition, Phoenix, AZ, USA, 20-23 March 2011; IEEE: Piscataway, NJ, USA, 2011; pp. 1-8.

20. Pourbeik, P. Proposed Changes to the WECC WT3 Generic Model for Type 3 Wind Turbine Generators; Prepared under Subcontract No. NFT-1-11342-01; EPRI: Palo Alto, CA, USA, 2013; Volume 12, p. 11.

21. Pourbeik, P.; Ellis, A.; Sanchez-Gasca, J.; Kazachkov, Y.; Muljadi, E.; Senthil, J.; Davies, D. Generic stability models for type $3 \& 4$ wind turbine generators for WECC. In Proceedings of the 2013 IEEE Power \& Energy Society General Meeting, Vancouver, BC, Canada, 21-25 July 2013; IEEE: Piscataway, NJ, USA, 2013; pp. 1-5.

22. Richwine, M.P.; Sanchez-Gasca, J.J.; Miller, N.W. Validation of a second generation Type 3 generic wind model. In Procedings of the 2014 IEEE PES General Meeting | Conference \& Exposition, National Harbor, MD, USA, 27-31 July 2014; IEEE: Piscataway, NJ, USA, 2014; pp. 1-4.

23. Pourbeik, P.; Etzel, N.; Wang, S. Model validation of large wind power plants through field testing. IEEE Trans. Sustain. Energy 2017, 9, 1212-1219. [CrossRef]

24. Lorenzo-Bonache, A.; Honrubia-Escribano, A.; Fortmann, J.; Gómez-Lázaro, E. Generic Type 3 WT models: Comparison between IEC and WECC approaches. IET Renew. Power Gener. 2019, 13, 1168-1178. [CrossRef]

25. Honrubia-Escribano, A.; Gomez-Lazaro, E.; Fortmann, J.; Sørensen, P.; Martin-Martinez, S. Generic dynamic wind turbine models for power system stability analysis: A comprehensive review. Renew. Sustain. Energy Rev. 2018, 81, 1939-1952. [CrossRef]

26. Coughlan, Y.; Smith, P.; Mullane, A.; O'Malley, M. Wind turbine modelling for power system stability analysis-A system operator perspective. IEEE Trans. Power Syst. 2007, 22, 929-936. [CrossRef]

27. Göksu, Ö.; Sørensen, P.E.; Morales, A.; Weigel, S.; Fortmann, J.; Pourbeik, P. Compatibility of IEC 61400-27-1 and WECC 2nd generation wind turbine models. In Proceedings of the 15th International Workshop on Large-Scale Integration of Wind Power into Power Systems as Well as on Transmission Networks for Offshore Wind Power Plants, Vienna, Austria, 15-17 November 2016.

28. Ausin, J.C.; Navarro Gevers, D.; Andresen, B. Fault Ride-through Capability Test Unit for Wind Turbines. Wind Energy 2008, 11, 3-12. [CrossRef]

29. Asmine, M.; Brochu, J.; Fortmann, J.; Gagnon, R.; Kazachkov, Y.; Langlois, C.E.; Larose, C.; Muljadi, E.; MacDowell, J.; Pourbeik, P.; et al. Model validation for wind turbine generator models. IEEE Trans. Power Syst. 2010, 26, 1769-1782. [CrossRef]

(C) 2019 by the authors. Licensee MDPI, Basel, Switzerland. This article is an open access article distributed under the terms and conditions of the Creative Commons Attribution (CC BY) license (http://creativecommons.org/licenses/by/4.0/). 